\title{
Role of verbal and non-verbal communication of health care providers in general satisfaction with birth care: a cross- sectional study in government health settings of Erbil City, Iraq
}

Hamdia Mirkhan Ahmed(D)

\begin{abstract}
Background: Effective communication by maternity care staff can help a woman during labor and birth have a positive birth experience. Due to limited knowledge regarding this topic in Iraqi Kurdistan, therefore, this study assessed: 1) The level of women's satisfaction regarding verbal and non-verbal communication of midwives and physicians in the delivery room and 2) the association between this satisfaction level and socio-demographic and obstetric characteristics of the women and their general satisfaction with care during labor and delivery.
\end{abstract}

Methods: A cross-sectional study was conducted on a convenient sample of 1196 women recruited between January and March 2019 from Erbil city, Iraq, who gave birth in the year before that. Data were collected from women through direct interview. A questionnaire which included sociodemographic, obstetrical information and 28 items related to verbal and non-verbal communication of physicians and midwives in the delivery room was used. Chi-square tests were used to find the association between dependent and independent variables.

Results: Although $58.4 \%$ of the women were generally satisfied with communication of midwives and physicians in the delivery room, a large percentage (41.6\%) were not satisfied. Only 14.6 and $27.3 \%$ of the women were completely satisfied with verbal and non-verbal communication of health care providers, respectively. There was a statistically significant association between women's satisfaction with care during labor and their satisfaction with health care providers' communication; $70.4 \%$ of women who were satisfied with care during birth were also satisfied with the communication of delivery room staff. There were statistically significant associations between the satisfaction of women with the communication of midwives and physicians and their level of education, parity, having stillbirth or neonatal death, and the setting of the last delivery.

Conclusions: Women's satisfaction with verbal and nonverbal communication of health care providers in the delivery room is associated with their satisfaction with birth care. Improving communication skills of health care providers can be a considerable part of improving care in delivery room.

Keywords: Communication, Personal communication, Women, Childbirth, Satisfaction

Correspondence: hamdia.ahmed@hmu.edu.krd; hamdia76@gmail.com College of Health Sciences, Center for Research and Education in Women's Health, Hawler Medical University, Erbil, Iraq 


\section{Plain English summary}

Effective communication by maternity care staff is an important factor for women's satisfaction with care during labor and delivery. This study assessed women's satisfaction with personal communication from health care providers including physicians and midwives in the delivery room. 1196 women participated. Results show that a relatively small percent of women were completely satisfied with the communication, although more than half of the women were generally satisfied with the communication. Seventy point $4 \%$ of those women who were satisfied with care during birth were also satisfied with communication of the delivery room staff. We concluded that women's satisfaction with verbal and nonverbal communication of health care providers in the delivery room is associated with their satisfaction with birth care.

\section{Background}

Delivery is one of the most important events in a woman's life, and one in which mental and physical stress is unavoidable [1]. This event is recognized as having deep mental, social, and emotional aspects that remain in the mother's consciousness forever; therefore, unpleasant events during delivery can have a negative long-term mental effect [2, 3].

During parturition, mothers need attention, understanding, empathy, guidance, and support in addition to clinical care [4]. They recognized the potential vulnerability of themselves and their baby through the process, and the essential uncertainty about what might happen. This was associated with a strong desire for safe, supportive, kind, respectful and responsive care during labor and birth. These characteristics applied to birth companions, professional and lay care givers, and to the processes and environment of care. Attitudes and behaviors of staff, the quality of the relationship between women and care providers, and the resources and atmosphere of the local facility has effect on women's experience [5]. Relevant studies show that a pivotal factor for a positive delivery experience is the comprehensive support of midwives. On the other hand, weak midwife communication skills could potentially have deleterious effects on physical, mental, social, and economical aspects of healthcare [1].

Effective communication by maternity care staff can help a woman during labor and birth to have a positive birth experience [6]. Childbirth can be a frightening experience for many women, but it should also be a joyous occasion and every woman should feel valued, respected, and appreciated by those who aid her in her journey of bringing new life into the world [7]. Effective communication between maternity care providers and women in labor, using simple and culturally acceptable methods, is recommended by the World Health Organization [8]. Therefore, enhancement of physicians' and midwives' communication skills is of key importance to promote the health of expecting mothers [9].

Studies performed in maternity wards showed that appropriate communication could be the main determining factor for satisfaction of mothers with the provided care [10]. An effective relationship between midwives and mothers can result in enhanced satisfaction, lowered blood pressure, anxiety, and pain, an increased sense of security, mutual trust, and interaction, an improved ability to make an informed decision, a reduced fear of a vaginal birth, an enhanced sense of assurance, better control of the delivery process, and most importantly, improved health [1].

Patient satisfaction is an important and commonly used indicator for measuring the quality of health care. Patient satisfaction affects clinical outcomes, patient retention, and medical malpractice claims. It affects the timely, efficient, and patient-centered delivery of quality health care. Patient satisfaction is thus a proxy but a very effective indicator to measure the success of doctors and hospitals [11].

Studies show that younger women, women with a low education level, rural residents and primiparas reported discrimination and unfriendly behaviors by providers and staff in the delivery room. As a result, they were not satisfied with their labor care [12-14]. No research could find on this subject in the Kurdistan region of Iraq; therefore, I investigated midwives' and physicians' communication skills in the delivery room in Erbil city, Iraq. This study assessed 1) women's perception about the quality of rapport between them and their providers in the delivery room; 2) the association between this satisfaction and sociodemographic characteristics of the women; and 3) the association between women's satisfaction and their general satisfaction with care during labor and delivery.

\section{Methods \\ Study population}

A cross-sectional study was conducted in Erbil city, in the Kurdistan region of Iraq during the period of January 20, 2019 to March 15, 2019. The inclusion criteria were having at least one birth experience (a vaginal delivery) within the past year, either in Rezgary hospital, a Maternity Teaching Hospital or Malafandy, a primary health center in Erbil city. Maternity Teaching Hospital is the biggest specialized public hospital for women's Health care especially labor and delivery care with 300 hundred beds and 30 beds in delivery room. Rezgary Hospital is a general hospital including a unit for women's health care services with capacity of 6 beds and Malafandy Primary Health Center has a small unit with capacity of 5 beds for labor and delivery care of women with low risk and normal health conditions. All of these institutions are public health settings. Women who delivered in a private hospital, had a psychological problem or were not 
interested in participating were excluded. Through convenient sampling, 1500 women were approached to participate in the study; 1234 met the inclusion criteria and 1196 women agreed to participate. These women were either accompanying another person to the hospital or health center, or coming to immunize one of their children.

\section{Data collection}

Data were collected through direct interview after we received informed consent. The purpose of the study was explained to the women and they were assured that all personal information would remain confidential. Three midwifery students helped the researcher with data collection after they were trained on how to interview women and collect the data.

A questionnaire was developed by the author after a massive review of literature which included two main parts: sociodemographic and obstetrical characteristics such as age, educational level, occupation, residency, parity, history of abortion, sex of the baby, admission of the baby to the ICU and 28 items related to verbal (16 items) and non-verbal (12 items) communication of physicians and midwives in delivery room [13-18].

\section{Outcome variables}

Responses to 28 items about the verbal and non-verbal communication of providers were scored as follows: a response of not satisfied was awarded 1 point, a response of don't know was awarded 2 points, and a response of satisfied was awarded 3 points. After obtaining the overall satisfaction of women, we summarized the results into two groups: satisfied and unsatisfied including both verbal and non-verbal communication items. Those who were not satisfied and "don't know" were merged together as don't know indirectly implied that women were not satisfied. Only a small percentage of the sample had allocated themselves to the "don't know" group. Those with a score of less than 56 (the midpoint between the minimum 28 and maximum 84 ) were considered as not satisfied and those with a score 57 to 84 were considered satisfied. Separately for verbal and nonverbal satisfaction, overall satisfaction was divided into four groups. For verbal communication items: completely not satisfied (those who received a total score of 16 points on the questionnaire, corresponding to not satisfied on every question), partly not satisfied (those who received a score between 17 and 32 points), partially satisfied (a total score of $33-47$ points) and completely satisfied (a total score of 48 points, indicating complete satisfaction on every one of the 16 items). For non-verbal communication items, the total score for the corresponding four categories were: 12 points, 13-24 points, $25-35$ points, and 36 points, respectively.
A separate question was asked regarding the general satisfaction with care during labor with three response of yes, no or partially.

\section{Exposure variables}

Exposure variables were age, educational level, occupation, residency, parity, having an abortion and stillbirth or neonatal death, the sex of the baby, admission of the baby to the ICU, having an episiotomy, and place of last delivery (a maternity hospital, Rezgary Hospital or Malafandi Center). The baby's sex, admission to the ICU, having an episiotomy and place of delivery described the mother's most recent delivery. Age was grouped as less than 20 years (which was considered an adolescent), 20 to 29,30 to 39 , and 40 or more years old. For educational level, basic means finishing 9 years of education, secondary means completing 12 years of education, and institute and BSc includes those who finished 2 years or more at a university. Residency is divided as urban which is Erbil city, suburban which includes towns within a half hour to one hour's drive from Erbil city, and rural, including towns and villages beyond the suburban areas. As most Kurdish women are housewives, occupation was grouped as housewife, employed or students. Parity was grouped as primipara (had one delivery), multipara (2 to 4 deliveries) and grand multipara (5 and more deliveries).

\section{Statistical analysis}

Data entered into and analyzed by SPSS program (Version 21) including frequency, percentage and chi-square test. Sociodemographic and obstetric data, satisfaction with verbal and nonverbal communication items and overall satisfaction were summarized by frequency and percentage. A chi-square test was used to find the association of general satisfaction with sociodemographic and obstetric variables. .

The study was approved by the Scientific Committee of the College of Nursing/Hawler Medical University.

\section{Results}

The sociodemographic characteristics of the study sample were as follows: almost half of the study sample was aged between 20 and 29 years old, The highest percentage $(40.8 \%)$ graduated from basic school, more than half (54.4\%) were from an urban area, and the majority of participants $(92.8 \%)$ were housewives. The highest percentage $(62.5 \%)$ of the women were multigravida, $34.2 \%$ had a history of abortion, $91.2 \%$ had no history of stillbirth or neonatal death, $63.6 \%$ experienced episiotomy or laceration during their most recent delivery and only $13.1 \%$ of their babies were admitted to the hospital NICU after delivery (Table 1).

Table 2 shows the satisfaction of participants with verbal and non-verbal communication of midwives and physicians during their labor and delivery. More than 
Table 1 Sociodemographic and obstetric characteristics of the study subjects ( $N=1196$, Erbil city, Iraq, 2019)

\begin{tabular}{|c|c|c|}
\hline Variables & Number & Percent \\
\hline \multicolumn{3}{|l|}{ Age group (years) } \\
\hline - less than 20 & 93 & 7.8 \\
\hline$-20-29$ & 597 & 49.9 \\
\hline$-30-39$ & 445 & 37.2 \\
\hline - 40 or more & 61 & 5.1 \\
\hline \multicolumn{3}{|l|}{ Education level } \\
\hline - illiterate & 268 & 22.4 \\
\hline - read and write & 168 & 14.0 \\
\hline - basic & 488 & 40.8 \\
\hline - secondary & 139 & 11.7 \\
\hline - institute $/ \mathrm{BSC}^{\mathrm{a}}$ & 133 & 11.1 \\
\hline \multicolumn{3}{|l|}{ Residency } \\
\hline - urban & 651 & 54.4 \\
\hline - suburban & 340 & 28.4 \\
\hline - rural & 205 & 17.1 \\
\hline \multicolumn{3}{|l|}{ Occupation } \\
\hline - housewife & 1110 & 92.8 \\
\hline - employed & 59 & 4.9 \\
\hline - student & 27 & 2.3 \\
\hline \multicolumn{3}{|l|}{ Parity } \\
\hline - primipara & 238 & 19.9 \\
\hline - multipara & 748 & 62.5 \\
\hline - grand multipara & 210 & 17.6 \\
\hline \multicolumn{3}{|c|}{ Number of abortions } \\
\hline - no abortion & 787 & 65.8 \\
\hline$-1-2$ & 356 & 29.8 \\
\hline - 3 and more & 53 & 4.4 \\
\hline \multicolumn{3}{|c|}{ Number of stillbirths } \\
\hline-0 & 1091 & 91.2 \\
\hline-1 & 88 & 7.4 \\
\hline$-2-3$ & 17 & 1.4 \\
\hline \multicolumn{3}{|c|}{ Episiotomy \& laceration (in most recent delivery) } \\
\hline - yes & 761 & 63.6 \\
\hline- no & 435 & 36.4 \\
\hline \multicolumn{3}{|l|}{ Sex of baby } \\
\hline - male & 589 & 49.2 \\
\hline - female & 607 & 50.8 \\
\hline \multicolumn{3}{|l|}{ Admission to $\mathrm{NICU}^{\mathrm{b}}$} \\
\hline - yes & 157 & 13.1 \\
\hline- no & 1039 & 86.9 \\
\hline
\end{tabular}

${ }^{a} B S C$ Baccalurius degree, ${ }^{b}$ NICU Neonatal Intensive Care Unit half of the study sample were not satisfied with this verbal communication: "introduce self" (66.5\%), "greeted the patient" (61.7\%), "checked the patient's understanding" (58\%), "asked whether patient had other issues or concerns" (50.2\%). Regarding non-verbal communication around two third of the women were satisfied with 11items from 12, described in Table 2 . The highest percentage (43.7\%) of the women not satisfied was for the item "maintain a patient's privacy during the physical examination."

Although $58.4 \%$ of the women were generally satisfied with the communication of midwives and physicians in the delivery room, a large percentage $(41.6 \%)$ were not satisfied. Only 14.6 and $27.3 \%$ of the women were completely satisfied with verbal and non-verbal communication of their health care providers, respectively (Table 3).

As Table 4 shows, there were statistically significant associations between the satisfaction of women with the communication of their midwives and physicians and the women's level of education $(p=0.021)$, parity $(p=0.002)$, and having a stillbirth $(p=0.023)$, as well as a highly significant association with the place of their last delivery $(\mathrm{p}=<0.001)$. The same table shows that there was a statistically significant association between women's satisfaction with their care during labor and their satisfaction with their health care providers' communication $(p=<0.001)$. Seventy point $4 \%$ of those women who were satisfied with care during birth were also satisfied with the communication of the midwives and physicians in the delivery room.

\section{Discussion}

In the present study, 1196 women were examined to find out their satisfaction with the communication of physicians and midwives during their labor and delivery and its relation with their overall satisfaction with received related care. The results show that the majority of women who were satisfied with their care were also satisfied with the communication of their health care providers. Only 14.6 and $27.3 \%$ of women were completely satisfied with all verbal and nonverbal communication items measured, respectively. Satisfaction with this communication was greater among women who were multigravida and grand multipara. As the women's education level increased, their satisfaction with the communication decreased which may due to this fact that educated women have a better understanding of the kind care possible given by health care providers. Age was not a significant factor in the satisfaction of women with communication.

The results of the present study regarding the association of satisfaction with sociodemographic characteristics of the women are in agreement with the results of many other studies. For instance, the results of a study done on 790 Australian women shows that parity, level of school-based education and place of residence were associated with differences in women's overall ratings of 
Table 2 Participant satisfaction with verbal and nonverbal communication of the midwives and physicians during their labor and delivery ( $N=1196$, Erbil city, 2019)

\begin{tabular}{|c|c|c|c|c|c|c|}
\hline \multirow{2}{*}{$\begin{array}{l}\text { Verbal communication } \\
\text { The provider... }\end{array}$} & \multicolumn{2}{|c|}{ Not Satisfied } & \multicolumn{2}{|c|}{ Don't know } & \multicolumn{2}{|c|}{ Satisfied } \\
\hline & No & $\%$ & No & $\%$ & No & $\%$ \\
\hline greeted the patient & 738 & 61.7 & 22 & 1.8 & 436 & 36.5 \\
\hline offered a seat to the patient & 461 & 38.5 & 25 & 2.1 & 710 & 59.4 \\
\hline introduced self to the patient & 795 & 66.5 & 38 & 3.2 & 363 & 30.4 \\
\hline used the patient's name & 448 & 37.5 & 36 & 3 & 712 & 59.5 \\
\hline used open questions to encourage the patient to freely provide information about her concerns & 385 & 32.2 & 42 & 3.5 & 769 & 64.3 \\
\hline encouraged the patient to speak as long as she needed to convey what she considered important & 363 & 30.4 & 55 & 4.6 & 778 & 65.1 \\
\hline verbally confirmed that they would respond to the patient's request & 342 & 28.6 & 92 & 7.7 & 762 & 63.7 \\
\hline carefully listened to the patient & 283 & 23.7 & 82 & 6.9 & 831 & 69.5 \\
\hline spoke in a calm and gentle manner & 269 & 22.5 & 68 & 5.7 & 859 & 71.8 \\
\hline used simple language that was easy to understand & 266 & 22.2 & 69 & 5.8 & 861 & 72 \\
\hline explained the examination and assessment & 547 & 45.7 & 94 & 7.9 & 555 & 46.4 \\
\hline explained patient's health problems and diagnosis & 573 & 47.9 & 103 & 8.6 & 520 & 43.5 \\
\hline discussed treatment options and offered choices & 507 & 42.4 & 105 & 8.8 & 584 & 48.8 \\
\hline provided information tailored to the patient's problems and concerns & 537 & 44.9 & 95 & 7.9 & 564 & 47.2 \\
\hline checked the patient's understanding of information & 693 & 58 & 101 & 8.4 & 402 & 33.6 \\
\hline asked whether the patient had other issues or concerns she would like to discuss & 600 & 50.2 & 105 & 8.8 & 491 & 41.1 \\
\hline \multicolumn{7}{|l|}{ Nonverbal communication } \\
\hline had a neat and tidy personal appearance & 304 & 25.4 & 168 & 14 & 724 & 60.5 \\
\hline made the patient feel welcome & 415 & 34.7 & 74 & 6.2 & 707 & 59.1 \\
\hline displayed patience when visiting with the patient & 320 & 26.8 & 82 & 6.9 & 794 & 66.4 \\
\hline maintained good eye contact with the patient & 323 & 27 & 95 & 7.9 & 778 & 65.1 \\
\hline used facial expressions to convey interest and attention & 312 & 26.1 & 97 & 8.1 & 787 & 65.8 \\
\hline used a caring and attentive body posture when approaching the patient & 300 & 25.1 & 87 & 7.3 & 809 & 67.6 \\
\hline used a professional tone of voice that also conveyed empathy and caring & 306 & 25.6 & 104 & 8.7 & 786 & 65.7 \\
\hline listened carefully and not interrupt the patient while speaking & 315 & 26.3 & 62 & 5.2 & 819 & 68.5 \\
\hline used nonverbal cues while listening to show attentiveness and empathy & 337 & 28.2 & 71 & 5.9 & 788 & 65.9 \\
\hline encouraged the patient to keep talking with posture and facial expressions & 333 & 27.8 & 68 & 5.7 & 795 & 66.5 \\
\hline maintain a patient's privacy during the physical examination & 522 & 43.7 & 81 & 6.8 & 593 & 49.6 \\
\hline visit patients individually rather than grouping them together & 390 & 32.6 & 100 & 8.4 & 706 & 59 \\
\hline
\end{tabular}

care; however, age was not associated with ratings of care [19]. In a 2016 study, labor observations and 2672 surveys in Ghana, Guinea, Myanmar, and Nigeria, age was predominantly the single factor associated with different types of mistreatment. Younger women (15-19 years) were more likely to experience any physical abuse, verbal abuse, or stigma or discrimination, after adjusting for country, education, marital status, and parity. Younger women with no education and younger women with some education were more likely to experience verbal abuse, compared with older women ( $\geq 30$ years) [14]. In a cross-sectional study by Okafor et al. in Enugu State in Nigeria, $20 \%$ of women reported discrimination on the basis of ethnicity, low social class, young age and HIV seropositive status, however, in four cross-sectional studies, women of low socioeconomic status and with no formal education reported experiences of unfriendly and harsh attitudes of staff in higher proportions [12].

Women in labor have a need for companionship, empathy and help, and descriptive studies of women's childbirth experiences have suggested four dimensions to the support that they want during labor: emotional support, informational support, physical support and advocacy [20]. Both the emotional and informational support depend on the communication skills of physicians and midwives.

The results of the present study are similar to results of other studies done in different countries which also show the importance of women's satisfaction with communication as an important factor in the general 
Table 3 Overall satisfaction of women with communication of midwives and physicians during their labor and delivery $(\mathrm{N}=$ 1196, Erbil city, 2019)

\begin{tabular}{ll}
\hline Level of satisfaction with communication & No. (\%) \\
\hline Overall satisfaction & \\
- not satisfied & $497(41.6)$ \\
- satisfied & $699(58.4)$ \\
Overall verbal communication & \\
- completely not satisfied & $51(4.3)$ \\
- partially not satisfied & $477(39.9)$ \\
- partially satisfied & $493(41.2)$ \\
- completely satisfied & $175(14.6)$ \\
Overall non-verbal communication & \\
- completely not satisfied & $42(3.5)$ \\
- partially not satisfied & $402(33.6)$ \\
- partially satisfied & $426(35.6)$ \\
- completely satisfied & $326(27.3)$ \\
\hline
\end{tabular}

satisfaction of women's birth care [20-22]. In a descriptive study from Iran, 50 midwives were evaluated by parturient women. The majority of them evaluated midwives' communicative behaviors at an acceptable level [1].

In an institution-based cross-sectional descriptive study from Ethiopia, a total of 423 postpartum women were interviewed to assess their satisfaction in a maternal health care setting. The results show that the proportion of mothers who were completely satisfied with the health care they received ranged between 2.4 to $21 \%$. The provider's communication with their clients yielded complete client satisfaction rates ranging between 0.7 to $26 \%$ [16].

Not being satisfied with provider communication was a reason for being dissatisfied with overall care among 400 women who delivered in a hospital in Egypt [23].

Results of a cross-sectional survey on 1004 women in India indicated that improving interpersonal interaction with nurse-midwives, and ensuring privacy during childbirth and the hospital stay are recommended first steps to improve women's childbirth satisfaction [15].

In a qualitative study from Nigeria, the quality of communication of health care providers in a delivery room was recognized as an important factor in improving women's experience of childbirth [24].

However, an increasing body of work over the last 20 years has demonstrated the relationship between doctors' non-verbal communication (in the form of eyecontact, head nods and gestures, position and tone of voice) with the following outcomes: patient satisfaction, patient understanding, physician detection of emotional distress, and physician malpractice claim history. Although more work needs to be done, there is now significant evidence that doctors need to pay considerable attention to their own non-verbal behavior [25].
Conversely, nonverbal dominance, in the form of long physician speaking time or a dominant tone of voice, for instance, has a negative impact on satisfaction [26]. Also, it has been shown that a physician's nonverbal behavior that expresses concern, for instance, through frequent eye contact, a concerned facial expression, or close interpersonal distance, leads to more patient trust than a physician's behavior that conveys more distance. Regarding patient adherence, it has been shown that physician touching of the patient increases patient adherence with their medication [26].

In a qualitative study on 16 mothers in Iran, results show that outcomes of a positive midwifemotherrelationship in the delivery room can lead to facilitation of childbirth, a positive birth experience, mental health promotion and improvement in the mother's quality of life. An effective midwife-mother relationship can lead to positive childbirth outcomes and promotion of maternal and neonatal health [21].

In a mixed-methods systematic review, a lack of evidence on the impact of interventions to support effective communication between maternity care staff and healthy women during labor and birth were identified [27]. A study from Syria reported that a communication skills training intervention for resident doctors were not associated with higher satisfaction reported by women. In the context of a highly crowded and stressful environment where middle-class and low-class Syrian women deliver, a specially-designed training package in interpersonal and communication skills for residents did not achieve an overall improvement in women's satisfaction with the doctor- woman relationship in labor and delivery rooms. However, certain items in the doctors' behavior have improved. It would be worth investigating whether the package would improve women's satisfaction in less stressful settings, but also it is worth looking at other possible interventions in maternity care practice such as doctor-midwife collaboration or attendance of birth companions in such settings. Despite the lack of evidence from these studies, the need to improve interpersonal skills of medical doctors and obstetricians specifically should be reinforced, as good communication is central to quality healthcare [28].

Verbal and nonverbal communication of health care providers in the delivery room have a significant impact on women's satisfaction with care, but we have to consider others factors, too. WHO recommends effective communication between maternity care providers and women in labor, however during the guideline development process, the Guideline Development Group (GDG) identified important knowledge gaps that need to be addressed through primary research regarding the effects of communication skills training on women's and providers' experiences, level, type and other characteristics 
Table 4 Association between sociodemographic, obstetric characteristics and birth outcome satisfaction with overall communication satisfaction ( $N=1196$, Erbil city, 2019)

\begin{tabular}{|c|c|c|c|}
\hline \multirow[t]{2}{*}{ Variables } & \multicolumn{2}{|c|}{ Overall satisfaction with provider communication } & \multirow{2}{*}{$\begin{array}{l}\boldsymbol{P} \text { - } \\
\text { value }\end{array}$} \\
\hline & $\begin{array}{l}\text { Not satisfied } \\
\text { No(\%) }\end{array}$ & $\begin{array}{l}\text { Satisfied } \\
\text { No(\%) }\end{array}$ & \\
\hline \multicolumn{4}{|l|}{ Age group } \\
\hline - less than 20 & $35(37.6)$ & $58(62.4)$ & \\
\hline$-20-29$ & $264(44.2)$ & $333(55.8)$ & 0.066 \\
\hline$-30-39$ & $181(40.7)$ & $264(59.3)$ & \\
\hline - 40 and more & $17(27.9)$ & $44(72.1)$ & \\
\hline \multicolumn{4}{|l|}{ Level of education } \\
\hline - illiterate & $103(38.4)$ & $165(61.6)$ & \\
\hline - read and write & $74(44)$ & $94(56)$ & 0.021 \\
\hline - basic & $185(37.9)$ & $303(62.1)$ & \\
\hline - secondary & $68(48.9)$ & $71(51.1)$ & \\
\hline - institute /BSC & $67(50.4)$ & 66 (49.6) & \\
\hline \multicolumn{4}{|l|}{ Occupation } \\
\hline - housewife & $460(41.4)$ & $650(58.6)$ & 0.944 \\
\hline - employed & $25(42.4)$ & $34(58.6)$ & \\
\hline - student & $12(44.4)$ & $15(55.6)$ & \\
\hline \multicolumn{4}{|l|}{ Residency } \\
\hline - urban & $261(40.1)$ & $390(59.9)$ & 0.230 \\
\hline - suburban & $140(41.2)$ & $200(58.8)$ & \\
\hline - rural area & $96(46.8)$ & $109(53.2)$ & \\
\hline \multicolumn{4}{|l|}{ Parity } \\
\hline - primipara & $120(50.4)$ & $118(49.6)$ & 0.002 \\
\hline - multipara & $284(38)$ & $464(62)$ & \\
\hline - grand multi para & $93(44.3)$ & $117(55.7)$ & \\
\hline \multicolumn{4}{|l|}{ Number of stillbirths } \\
\hline - none & $461(42.3)$ & $630(57.7)$ & 0.023 \\
\hline - one & $26(29.5)$ & $62(70.5)$ & \\
\hline - two to three & $10(58.8)$ & $7(41.2)$ & \\
\hline \multicolumn{4}{|l|}{ Number of abortions } \\
\hline - none & $336(42.7)$ & $451(57.3)$ & 0.492 \\
\hline - one to two & $106(40.2)$ & $158(59.8)$ & \\
\hline - three and more & $55(37.9)$ & $90(62.1)$ & \\
\hline \multicolumn{4}{|l|}{ Admission to $\mathrm{NICU}^{\mathrm{a}}$} \\
\hline - yes & $74(47.1)$ & $83(52.9)$ & 0.128 \\
\hline- no & $423(40.7)$ & $616(50.3)$ & \\
\hline \multicolumn{4}{|l|}{ Sex of baby } \\
\hline - male & $247(41.9)$ & $342(58.1)$ & 0.793 \\
\hline - female & $250(41.2)$ & $357(58.8)$ & \\
\hline \multicolumn{4}{|l|}{ Place of last delivery } \\
\hline - a maternity hospital & $429(39.1)$ & $667(60.9)$ & $<0.001$ \\
\hline - Rezgary Hospital & $66(71.7)$ & $26(28.3)$ & \\
\hline - Malafandi Center & $2(25)$ & $6(75)$ & \\
\hline
\end{tabular}

Had episiotomy 
Table 4 Association between sociodemographic, obstetric characteristics and birth outcome satisfaction with overall communication satisfaction ( $N=1196$, Erbil city, 2019) (Continued)

\begin{tabular}{|c|c|c|c|}
\hline \multirow[t]{2}{*}{ Variables } & \multicolumn{2}{|c|}{ Overall satisfaction with provider communication } & \multirow{2}{*}{$\begin{array}{l}P \text { - } \\
\text { value }\end{array}$} \\
\hline & $\begin{array}{l}\text { Not satisfied } \\
\text { No(\%) }\end{array}$ & $\begin{array}{l}\text { Satisfied } \\
\text { No(\%) }\end{array}$ & \\
\hline - yes & $324(42.6)$ & $437(58.4)$ & 0.344 \\
\hline- no & $173(39.8)$ & $262(60.2)$ & \\
\hline \multicolumn{4}{|c|}{ Generally satisfied with care during birth } \\
\hline - yes & $276(29.6)$ & $658(70.4)$ & $<0.001$ \\
\hline- no & $177(93.7)$ & $12(6.3)$ & \\
\hline - partially & $44(60.3)$ & $29(39.7)$ & \\
\hline
\end{tabular}

${ }^{\mathrm{a} N I C U}$ neonatal intensive care unit

of communication and optimal skilled birth attendant to-woman ratio for delivery of effective communication [8]. Further studies are needed to more precisely identify the role of communication in women's satisfaction during labor and delivery by considering all aspects of care.

\section{Strengths and limitations}

This study included a large sample size. Additionally, studying verbal and non-verbal communication was a strength of the present study, whereas the convenient sampling approach and limiting our sample to include only the experiences of births in public hospitals were limitations.

\section{Conclusions}

The overall satisfaction of women with the communication of their health care providers in the delivery room was $58.4 \%$. A relatively small proportion (14.6, 27.3\%) of women were completely satisfied with verbal and nonverbal communication of health care providers in the delivery room, respectively. The majority of women who were generally satisfied with their birth care were also satisfied with the communication of physicians and midwives during birth. The results of the present study have clarified one necessary aspect for quality improvement in intrapartum care in maternity hospitals of the Kurdistan region of Iraq. Health policy makers and stakeholders can play an important role in developing strategies for improving communication skills of health care providers.

\section{Abbreviations \\ WHO: World Health Organization; NICU: Neonatal Intensive Care Unit}

\section{Acknowledgements}

Many thanks for Ms. Aras Shakr Aziz, Ms. Kawthar Hassan Sleman and Ms. Chenar Yasin MuhammadAmin (three midwifery students) who help the researcher in collecting data. Pre-Publication Support Service (PREPSS) supported the development of this manuscript by providing pre-publication peer-review and copy editing.

\section{Author's contribution}

HMA initiated the idea, prepared the proposal, analyzed and interpreted the patient data regarding their quality of life and wrote and approved the final manuscript.

\section{Authors' information}

Hamdia Mirkhan Ahmed is the dean of College of Health Sciences and also Director of the Center for Research and Education in Women's Health in Hawler Medical University, Erbil, Kurdistan Region, Iraq.

Funding

Not applicable.

Availability of data and materials

The datasets used and/or analyzed during the current study are available from the corresponding author on reasonable request.

\section{Ethics approval and consent to participate}

The proposal of the study approved by Scientific Committee of College of Nursing/Hawler Medical University. Informed consent was taken from all study participants.

\section{Consent for publication}

Not applicable.

\section{Competing interests}

The author declares that he/she has no competing interests.

Received: 12 December 2019 Accepted: 5 March 2020

Published online: 09 March 2020

\section{References}

1. Katebi MS, Khadivzadeh T, Shamloo ZS, Esmaily H. Evaluating midwives communication skills from the perspective of parturient women attending to hospitals for delivery. J Midwifery Reprod Health. 2017;5(2):882-9.

2. Taghizadeh ZI, Razaiepour A, Mehran AB, Alimardani Z. Usage of communication skills by midwives and its relation to client satisfaction. J Hayat. 2007:12(4):47-55.

3. Baker DP, Salas E, King H, Battles J, Barach P. The role of teamwork in professional education of physicians: current status and assessment recommendation. Joint Comm J Qual Patient Saf. 2005;31(4):185-202.

4. Vafaei Z, Javadnoori M, Najar N, Latifi SM. Barriers of effective communication between midwives and parturient women in hospitals of Khuzestan Province, Iran, 2012. Iran J Obstetrics Gynecol Infertil. 2013;15(40):10-5.

5. Downe S, Finlayson K, Oladapo O, Bonet M, Gulmezoglu M. What matters to women during childbirth: a systematic qualitative review. PLoS One. 2018; 13(4):e0194906. https://doi.org/10.1371/journal.pone.0194906.

6. Delgado V, Gholitabar M, Sims JM, Bewley S. Intrapartum care of healthy women and their babies: summary of updated NICE guidance. BMJ. 2014; 349:g6886. https://doi.org/10.1136/bmj.g6886.

7. Windau-Melmer T. A Guide for Advocating for Respectful Maternity Care. Washington: Futures Group, Health Policy Project; 2013. https:/www. whiteribbonalliance.org/wp-content/uploads/2017/11/RMC-Guide_FINAL.pdf.

8. $\mathrm{WHO}$. WHO recommendations Intrapartum care for a positive childbirth experience. https//apps who.int/ins/bitstream/handle/10665/260178/9789241550215-eng.pdf. Accessed 24 Mar 2019.

9. White Ribbon Alliance. Respectful maternity care: the universal rights of childbearing women. White Ribbon Alliance 2011. https://www. whiteribbonalliance.org/wp-content/uploads/2017/11/Final_RMC_Charter. pdf. Accessed 14 Apr 2019. 
10. Freedman LP, Kruk ME. Disrespect and abuse of women in childbirth: challenging the global quality and accountability agendas. Lancet. 2014 https://doi.org/10.1016/50140-6736(14)60859-X.

11. Prakash B. Patient Satisfaction. J Cutan Aesthet Surg. 2010;3(3):151-5.

12. Ishola F, Owolabi O, Filippi V. Disrespect and abuse of women during childbirth in Nigeria: a systematic review. PLoS One. 2017;12(3):e0174084.

13. Brown S, Lumley J. Satisfaction with care in labor and birth: A survey of 790 Australian Women. Birth. 1994;21(1):4-13.

14. Bohren M, Mehrtash H, Fawole B, Maung T, Balde M, Maya E. How women are treated during facility-based childbirth in four countries: a cross-sectional study with labor observations and community-based surveys. Lancet. 2019;394:1750-63.

15. Jhaa P, Larsson M, Christensson K, Svanberg AS. Satisfaction with childbirth services provided in public health facilities: results from a cross- sectional survey among postnatal women in Chhattisgarh, India. Global Health Action. 2017:10:1386932.

16. Melese T, Gebrehiwot Y, Bisetegne D, Habte D. Assessment of client satisfaction in labor and delivery services at a maternity referral hospital in Ethiopia. Pan Afr Med J. 2014;17:76. https://doi.org/10.11604/pamj.2014.17.76.3189.

17. World Health Organization (WHO). WHO recommendation on effective communication between maternity care providers and women in labour. The WHO Reproductive Health Library. 2018. https://extranet.who.int/rhl/ topics/preconception-pregnancy-childbirth-and-postpartum-care/careduring-childbirth/who-recommendation-effective-communication-betweenmaternity-care-providers-and-women-labour. Acceced May 2019.

18. Grobman WA, Holl J, Woods D, Gleason KM, Wassilak B, Szekendi MK. Perspectives on communi cation in labor and delive ry: a focus group analysis. J Perinatol. 2011;31:240-5.

19. Brown SW, Nelson AM, Bronkesh SJ, Wood SD. Quality service for practice success. Maryland: Aspen publication; 1993. Patient Satisfaction Pays.

20. The Royal College of Midwives. Evidence based guidelines for MidwiferyLed care in labor. 2012. Accessed 20 Nov 2019. https://www.academia. edu/35976988/Evidence_Based_Guidelines_for_Midwifery-Led_Care_in_ Labour_Positions_for_Labour_and_Birth.

21. Attarha M, Keshavarz Z, Bakhtiari M, Jamilian M. The outcome of midwifemother relationship in delivery room: a qualitative content analysis. Health. 2016;8:336-43. https://doi.org/10.4236/health.2016.84035.

22. Nilsson $L$, Thorsell $T$, Wahn E, Ekström A. Factors influencing positive birth experiences of first-time mothers. Nurs Res Pract. 2013;2013:349124. https//doi.org/10.1155/2013/349124.

23. Sayed W, AbdEIAal DE, Mohammed HS, Abbas AM, Zahran KM. Maternal satisfaction with delivery services at tertiary university hospital in upper Egypt, is it actually satisfying? Int J Reprod Contracept Obstet Gynecol. 2018 7(7):2547-52. https://doi.org/10.18203/2320-1770.ijrcog20182859.

24. Ojelade OA, Titiloye MA, Bohren MA, Olutayo AO, Olalere AA, Akintan A, et al. The communication and emotional support needs to improve women's experience of childbirth care in health facilities in Southwest Nigeria: a qualitative study. Int J Gynecol Obstet. 2017;139(Suppl. 1):27-37. https://doi.org/10.1002/ijgo.12380.

25. Silverman J, Kinnersley P. Doctors'non-verbal behaviour in consultations: look at the patient before you look at the computer. Br J Gen Pract. 2010; 60(571):76-8. https://doi.org/10.3399/bjap10X482293.

26. Mast MS, Cousin G. The role of nonverbal communication in medical interactions: Empirical results, theoretical bases, and methodological issues. In: Martin LR, DiMatteo R. The Oxford Handbook of Health Communication, Behavior Change, and Treatment Adherence, 2013. https://www. researchgate.net/publication/282849046_The_role_of_nonverbal_ communication_in_medical_interactions_Empirical_results_theoretical_ bases_and_methodological_issues. Accessed Jun 262019.

27. Chang Y, Coxon K, Portela AG, Furuta M, Bick D. Interventions to support effective communication between maternity care staff and women in labor: A mixed-methods systematic review. 2018;59:4-16. https://doi.org/10.1016/j. midw.2017.12.014

28. Bashour H, Kanaan M, Kharouf MH, Abdulsalam AA, Tabbaa MA, Cheikha S, et al. The effect of training doctors in communication skills on women's satisfaction with doctor-woman relationship during labor and delivery: a stepped wedge cluster randomized trial in Damascus. BMJ Open. 2013;3: e002674. https://doi.org/10.1136/bmjopen-2013-002674.

\section{Publisher's Note}

Springer Nature remains neutral with regard to jurisdictional claims in published maps and institutional affiliations.

\section{Ready to submit your research? Choose BMC and benefit from:}

- fast, convenient online submission

- thorough peer review by experienced researchers in your field

- rapid publication on acceptance

- support for research data, including large and complex data types

- gold Open Access which fosters wider collaboration and increased citations

- maximum visibility for your research: over $100 \mathrm{M}$ website views per year

At $\mathrm{BMC}$, research is always in progress.

Learn more biomedcentral.com/submissions 